\title{
From the institute's Photo Library
}

\author{
doi:10.1111/j.1751-8369.2010.00159.x
}

Hanna Marie Resvoll-Holmsen (1873-1943) poses in front of a glacier debouching into the fjord Lilliehöökfjorden, a branch of Krossfjorden, in western Spitsbergen, in 1908. The pioneering Norwegian botanist carried out fieldwork in the Arctic archipelago of Svalbard during expeditions sponsored by Prince Albert I of Monaco in 1907 and 1908. ResvollHolmsen was put ashore with her tent and provisions at remote locations along the coast. She worked industriously, mapping vegetation on the western side of Spitsbergen, discovering new species and laying groundwork for subsequent investigations of the archipelago's plant communities. Resvoll-Holmsen thrived on her solitude in the harsh wilderness. Alone in her little camp in Colesbukta, she wrote: "Time passes far too quickly. Tent life is wonderful ..." A skilled photographer, Resvoll-Holmsen was among the first Norwegian scientists to make use of colour photography, which she first experimented with in Svalbard.

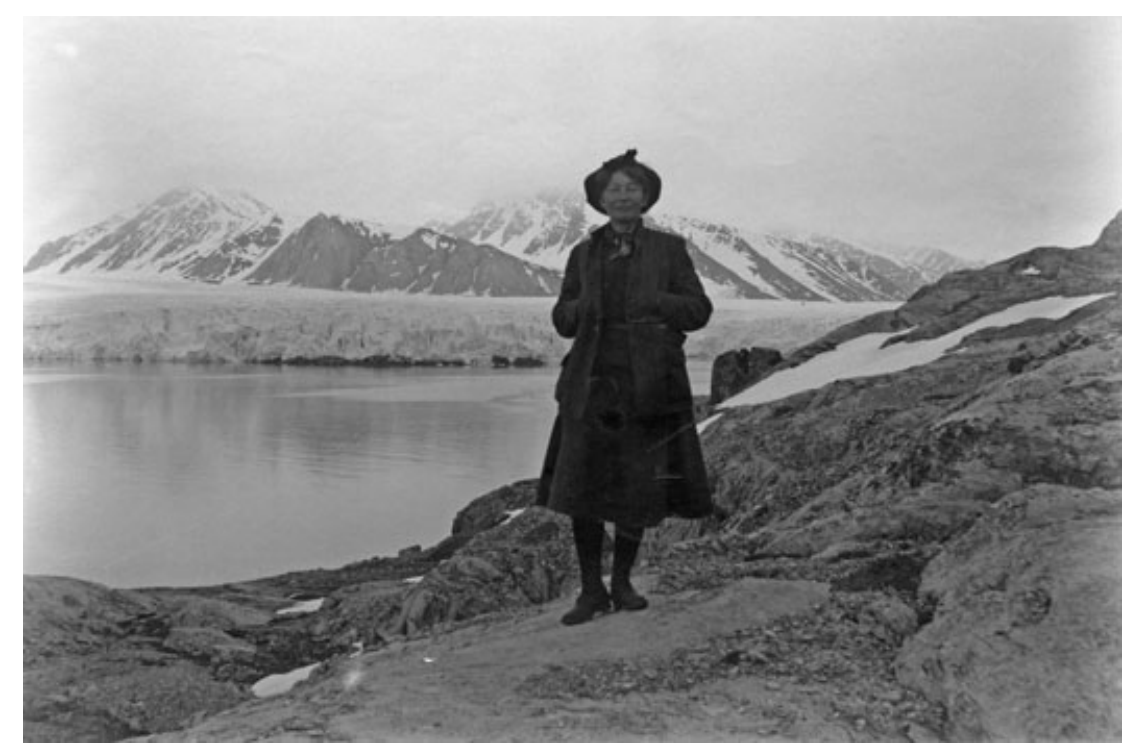

The Norwegian Polar Institute's Photo Library preserves some 90000 polar-related images captured during the last 135 years, including glass plates and slides, stereo images, print photographs and modern digital photographs. Images documenting Norwegian activities in the Arctic and Antarctic comprise the bulk of the collection. Scanning the older images and registering newer digital ones is an ongoing endeavour. To date, digital versions of over 30000 pictures are available in a searchable online database at http://sivert.npolar.no/fotoweb/. Search words associated with the online images are mostly in the Norwegian language; please send an e-mail to bildearkiv@npolar.no for assistance in searching the database. 